\title{
ARSITEKTUR WEB SERVICE DI LEMBAGA PENDIDIKAN MA'ARIF DEMAK
}

\author{
Ahmad Jazuli ${ }^{1}$, Anastasya Latubessy ${ }^{2}$, Ratih Nindyasari $^{3}$ \\ ${ }^{123}$ Universitas Muria Kudus \\ Email: ${ }^{1}$ ahmad.jazuli@umk.ac.id, ${ }^{2}$ anastasya.latubessy@umk.ac.id, ${ }^{2}$ ratih.nindyasari@umk.ac.id
}

(Naskah masuk: 2 Maret 2021, diterima untuk diterbitkan: 24 Juni 2021)

\begin{abstract}
Abstrak
Lembaga Pendidikan terus berinovasi dan beradaptasi ditengah Pandemi dengan memanfaatkan teknologi informasi. Lembaga Pendidikan Ma'arif Demak membawahi MI, MTS, dan MA. Setiap MI, MTS, dan MA ini memiliki sistemnya sendiri dengan database masing-masing. Sementara, Lembaga Pendidikan Ma'arif Demak mengiginkan adanya sistem terintegasi yang dapat mengakses semua data MI, MTS, dan MA tersebut. Berangkat dari permasalahan tersebut, penelitian ini merancang arsitektur web service yang sesuai dengan kebutuhan di Lembaga Pendidikan Ma'arif Demak. Arsitektur ini kemudian, diuji dengan melakukan simulasi menggunakan model REST API.
\end{abstract}

Kata kunci: arsitektur, web service, REST API, Pendidikan

\section{WEB SERVICE ARCHITECTURE IN DEMAK MA'ARIF EDUCATION INSTITUTION}

\begin{abstract}
Educational institutions continue to innovate and adapt in the midst of a pandemic by utilizing information technology. The Ma'arif Demak Education Institute oversees MI, MTS, and MA. Each MI, MTS, and MA has its own system with their respective databases. Meanwhile, the Ma'arif Demak Education Institute wants an integrated system that can access all MI, MTS, and MA data. Departing from these problems, this study designs a web service architecture that suits the needs of the Ma'arif Demak Educational Institute. This architecture is then tested by performing a simulation using the REST API model.
\end{abstract}

Keywords: architecture, web service, REST API, education

\section{PENDAHULUAN (huruf besar, 10pt, tebal)}

Dimasa pandemi seperti sekarang, Lembaga pendidikan perlu beradaptasi dan memanfaatkan kecanggihan teknologi informasi agar dapat terus menjalankan tugas dan fungsinya dengan tepat baik. Lembaga pendidikan dituntut untuk memanfaatkan teknologi informasi yang ada. Kehadiran teknologi seperti pemanfaatan website Pendidikan sangat membantu sebagai sarana dalam berbagi informasi dan pengetahuan.

Saat ini, setiap sekolah baik sekolah negeri maupun swasta telah memiliki sistem akademik masing-masing yang diolah secara komputerisasi. Sistem akademik ini akan terhubung ke database masing-masing guna proses penyimpanan data. Tentu dengan adanya media penyimpanan sendirisendiri data dapat diolah secara mandiri.

Permasalahan kemudian muncul ketika sekolah-sekolah tersebut dikelola oleh satu Yayasan yang sama. Yayasan tersebut menginginkan adanya sinkronisasi data agar dapat diakses pada sebuah portal yang dikelola di Yayasan. Hal tersebut dijumpai di Lembaga Pendidikan Ma'arif Demak. Lembaga Pendidikan Ma'arif Demak membawahi ratusan sekolah ma'arif yang ada di Demak mulai dari MI, MTS dan MA. Permasalahan yang dialami oleh Lembaga Pendidikan Maarif Demak adalah kesulitan dalam proses pengelolaan Sinkronisasi Data dari berbagai sekolah yang berada dibawah koordinasi Lembaga Pendidikan Maarif Demak.

Berdasarkan permasalahan tersebut, penelitian ini merancang sebuah arsitektur web service yang dapat digunakan untuk proses sinkronisasi data yang ada pada sistem akademik yang dimiliki oleh MI, MTS, dan MA yang ada dibawah koordinasi Lembaga Pendidikan Ma'arif Demak.

Model web service yang digunakan dalam penelitian ini adalah model REST API. Menurut Verborgh et al (2017), API yang mengikuti prinsip REST adalah "native Web citizens", berarti API tersebut bekerja dengan berdasar kepada prinsip kerja Web. Dengan adanya pernyataan tersebut, 
membuat REST API lebih baik dibandingkan web service tradisional.

Beberapa penelitian serupa yang pernah dilakukan oleh peneliti lain antara lain, Rahim, A dan Mulyadi, 2019 dalam penelitiannya yang melakukan Optimalisasi Proses Sinkronisasi Data terhadap Sistem Akademik dan Web Services PD DIKTI. Teknologi yang digunakan adalah Fitur Queues yang terdapat di Framework Laravel.

Sitorus, Z., dkk pada tahun 2018 juga melakukan analisa terhadap kebutuhan web service untuk proses sinkronisasi data antar sistem informasi di suatu Universitas. Hal serupa juga pernah dilakukan oleh Sutanta, E dan Mustofa, K., 2012 dalam penelitiannya yang dipublikasikan pada Jurnal Teknologi dan Komunikasi. Dalam penelitian tersebut dilakukan analisa kebutuhan web service untuk sinkronisasi sistem informasi dalam e-gov di pemkab Bantul, Yogyakarta.

Implementasi web service pada bidang akademik sering sekali dilakukan seperti pada penelitian Perwira,R.I dan Santosa, B., 2017 yang melakukan implementasi web service pada integrasi data akademik dengan memanfaatkan replica pangkalan data DIKTI.

Beberapa penelitian terdahulu yang pernah dilakukan oleh Peneliti antara lain: Implementasi Fungsi REST Pada Web Service yang diterapkan pada Portal Berita Di SMK Islam Al Hikmah Mayong Jepara, Taib, H., Nurkamid, M., dan Latubessy, A., 2015. Penelitian ini membahas bagaimana representasi dan sinkronisasi antar basis data relasional dapat dilakukan dengan studi kasus pada Implementasi Fungsi REST Pada Web Service untuk Portal Berita di SMK Islam Al Hikmah Mayong Jepara. Integrasi basis data yang dibangun dengan menggunakan teknologi REST bertujuan sebagai sarana untuk menampilkan daftar informasi berita, dan kegiatan yang ada di website SMK Islam Al Hikmah Mayong Jepara. Dengan memanfaatkan web service, maka distribusi data informasi berita di SMK Islam Al Hikmah Mayong dapat dilakukan.

Penelitian serupa yang pernah dilakukan peneliti dengan memanfaatkan metode Web Service adalah Implementasi Sistem Interkoneksi Basis Data Terdistribusi Menggunakan Socket API pada Sistem Kepegawaian di Dinas Infokom Provinsi Maluku, Latubessy,A., dan Ashari, A., 2012. Hasil yang diperoleh dalam penelitian ini adalah aplikasi socket sebagai middleware yang menangani distribusi data dari aplikasi web client ke dua server basis data yang diimplementasikan pada sistem kenaikan gaji berkala otomatis di Dinas Infokom Provinsi Maluku.

Selain itu, anggota peneliti lain juga pernah melakukan penelitian dibidang web service yaitu, melakukan implementasi web service untuk pengelolaan Rekam Medis pada Klinik Bersalin Fatma Medika, Ahsin, M., Jazuli,A., dan Khotimah, T., 2015 Kekurangan dan keterbatasan dalam integrasi data antara klinik cabang dengan klinik pusat, maka pada penelitian yang dilakukan oleh Ahsin, M., dkk melakukan pembuatan model akses database yang berbasis web services pada Klinik Fatma Medika. Hal ini dilakukan agar data yang ada pada tiap cabang Klinik Fatma Medika dapat saling terintegrasi dan saling tersinkronisasi dengan klinik pusat serta sebaliknya; yang tentunya akan berdampak positif pada sisi pasien dan admin untuk tiap klinik cabang dan klinik pusat dalam melakukan kegiatan rekam medis.

\section{METODE PENELITIAN}

Menggunakan metode pengembangan sistem waterfall dengan tahapan-tahapan yang digunakan dalam penelitian ini antara lain :

Identifikasi Sistem: Pada tahap ini akan dilakukan pengumpulan data. Dilakukan identifikasi terhadap kebutuhan dengan merumuskan data yang dapat digunakan untuk merancang sistem. Identifikasi dilakukan dengan berdiskusi dengan mitra yang dalam hal ini adalah LP. Maarif Demak. Diskusi dilakukan secara online dan onsite. Online menggunakan teknologi Google Meet. Sementara onsite dilakukan secara tatap muka langsung di UMK. Diskusi dilakukan untuk mencapai kesepahaman tentang apa yang dibutuhkan oleh mitra.

Analisa Sistem: dilakukan analisa kebutuhan sistem baik fungsional maupun non fungsional.Dilakukan analisa kebutuhan terhadap ketersediaan Sistem dan Website yang ada di lingkungan Lembaga Pendidikan Ma'arif Demak.

Perancangan Sistem: Pada tahap Perancnagan sistem dilakukan perancangan proses dan perancangan tampilan.

Implementasi Website: Dilakukan dengan menggunakan Bahasa Pemrograman PHP dan Basisdata MySQL untuk website Lembaga Pendidikan Ma'arif.

Simulasi Web service: Dilakukan simulasi dengan metode web service. Simulasi web service yang akan dilakukan ditunjukkan pada Gambar 1 . Dimana, fungsi-fungsi pada setiap database pada sistem yang tersebar di LP. Ma'arif Demak akan disinkorinisasi dengan Web service sehingga dapat digunakan dan diakses oleh setiap perangkat secara realtime.

Testing Sistem: Pengujian terhadap hasil simulasi web service. Testing dilakukan dalam dua tahapan yaitu Blackbox Testing.

\section{HASIL DAN PEMBAHASAN}

Lembaga Pendidikan Maarif Demak menghendaki adanya sistem terintegrasi antara MI, MTS, dan MA. Lembaga Pendidikan Maarif Demak menghendaki adanya sebuah website yang mendukung kegiatan guru dan siswa. Lembaga Pendidikan Maarif Demak menghendaki dibuatkan 
website yang mewadahi kegiatan Musyawarah Guru Mata Pelajaran (MGMP). Lembaga Pendidikan Maarif Demak menghendaki dibuatkan website yang mewadahi kegiatan Kelompok Kerja Madrasah (KKM).

\subsection{Rancangan Arsitektur Web Service}

Arsitektur web service sistem di Lembaga Pendidikan(LP) Ma'arif Demak ditunjukkan pada Gambar 1. Terdapat satu Portal yang dimiliki oleh LP Ma'arif Demak yang memiliki database-nya sendiri. Sementara MI, MTS, dan MA memiliki sistem akademiknya sendiri yang terhubung pada database masing-masing.

Pada penelitian ini model web service yang digunakan untuk proses sinkronisasi adalah model REST API. REST API terhubung ke Sistem Akademik yang ada di MI, MTS, dan MA melalui proses request dan repsonse.

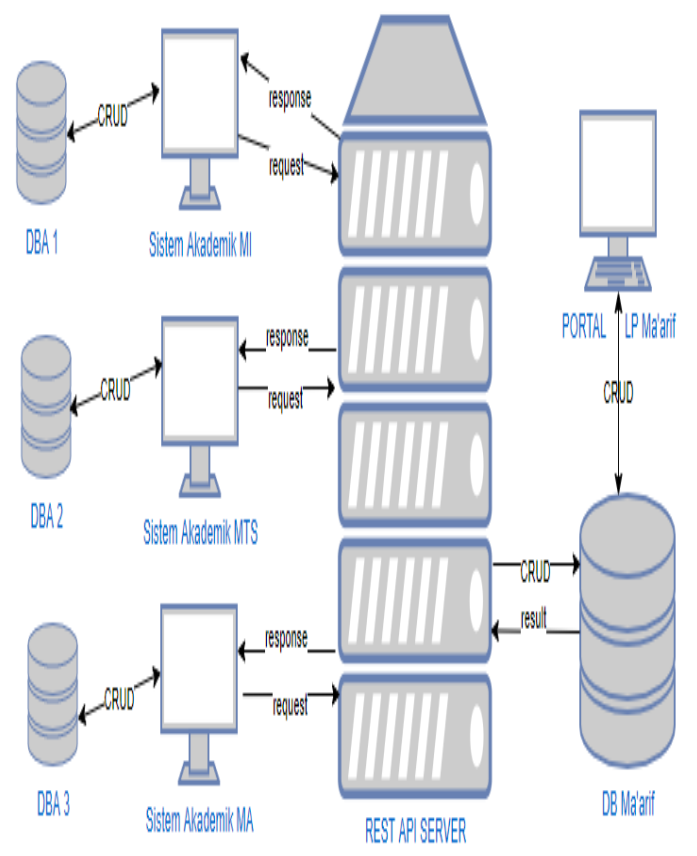

Gambar 1. Rancangan Arsitektur Web Service LP Ma'arif Demak

DBA 1 merupakan database yang terhubung ke sistem akademik MI. DBA 2 merupakan database yang terhubung ke sistem akademik MTS. DBA 3 merupakan database yang terhubung ke sistem akademik MA.

\subsection{Pengujian}

Testing yang pertama dilakukan dengan metode blackbox testing, untuk menguji kerja sistem, apakah sudah berjalan sesuai dengan yang fungsionalitasnya. Oleh sebab itu scenario yang dibuat dalam proses pengujian ditunjukkan pada Tabel 1. Proses yang diujikan adalah proses login.

\begin{tabular}{|c|c|c|}
\hline No & Skenario & Hasil \\
\hline 1. & $\begin{array}{l}\text { Pengujian proses login: } \\
\text { Jika username dan password } \\
\text { salah }\end{array}$ & Login gagal \\
\hline 2. & $\begin{array}{l}\text { Pengujian proses login: } \\
\text { Jika username salah dan } \\
\text { password benar }\end{array}$ & Login gagal \\
\hline 3. & $\begin{array}{l}\text { Pengujian proses login: } \\
\text { Jika username benar dan } \\
\text { password salah }\end{array}$ & Login gagal \\
\hline 4. & $\begin{array}{l}\text { Pengujian proses login: } \\
\text { Jika username dan password } \\
\text { kosong }\end{array}$ & Login gagal \\
\hline 5 . & $\begin{array}{l}\text { Pengujian proses login: } \\
\text { Jika username benar dan } \\
\text { password kosong }\end{array}$ & Login gagal \\
\hline 6. & $\begin{array}{l}\text { Pengujian proses login: } \\
\text { Jika username kosong dan } \\
\text { password benar }\end{array}$ & Login gagal \\
\hline 7. & $\begin{array}{l}\text { Pengujian proses login: } \\
\text { Jika username kosong dan } \\
\text { password benar }\end{array}$ & Login berhasil \\
\hline 8. & $\begin{array}{l}\text { Pengujian simulasi web service } \\
\text { proses login }\end{array}$ & Berhasil \\
\hline
\end{tabular}

\section{KESIMPULAN DAN SARAN}

Berdasarkan hasil pengujian rancangan arsitektur web service pada sistem akademik di MI, MTS dan MA Yayasan Ma'arif Demak membutuhkan REST API web service dalam sinkronisasi data, sehingga data-data yang secara terpisah pada database masing-masing sistem dapat diakses pada Portal Lembaga Pendidikan Ma'arif Demak.

\section{UCAPAN TERIMA KASIH}

Terima kasih diucapkan kepada Lembaga Pendidikan Maarif Demak atas kerjasamanya dan kepercayaannya kepada Tim Peneliti untuk menyelesikan simulasi web service di sistem akademik Lembaga Pendidikan Maarif Demak. Terima kasih juga diucapkan kepada Lembaga Penelitian dan Pengabdian kepada Masyarakat(LPPM) Universitas Muria Kudus, atas dukungan berupa dana yang diberikan sehingga penelitian ini dapat terlaksana tanpa kurang suatu apapun.

\section{DAFTAR PUSTAKA}

Verborgh, R., Arndt, D., Van Hoecke, S., De Roo, J., Mels, G., Steiner, T., \& Gabarro, J. (2017). The pragmatic proof: Hypermedia API composition and execution. Theory and Practice of Logic Programming, 17(1), $1-48$.

Rahim, A., dan Mulyadi, 2019, Optimalisasi Proses Sinkronisasi Data Akademik dan Web Services PPDIKTI Menggunakan Fitur 
Queues Pada Framework Laravel, Jurnal Ilmiah Sistem Informsi, Teknologi Informasi dan Sistem Komputer, Vol.14 No.1. ISSN 1907-6738.

Sitorus,Z., dkk, 2018, Kebutuhan Web Service untuk Sinkronisasi Data Antar Sistem Informasi dalam Universitas, Junral Teknik dan Informatika, Vol 5 No.2. ISSN 2089-5490.

Perwira, R.I., dan Santosa, B., 2017, Implementasi Web Service pada Integrasi Data Akademik Dengan Replika Pangkalan Data DIKTI, Jurnal Telematika, Vol.14 No.1, ISSN 1829-667X.

Sutanta, E., dan Mustofa, K., 2012, Kebutuhan Web Services untuk Sinkronisasi Sistem Informasi dalam E-Gov di Pemkab Bantul Yogyakarta, Jurnal Teknologi Informasi dan Komunikasi Vol.1 No.1.

Ahsin, M., Jazuli,A., dan Khotimah, T., 2015, Implementasi Rekam MediS pada Klinik Bersalin Fatma Medika Berbasis Web Service, SKRIPSI, Teknik Informatika UMK, https://eprints.umk.ac.id/4247/

Taib, H., Nurkamid, M., dan Latubessy, A., 2015, Implementasi Fungsi REST Pada Web Service Untuk Portal Berita Di Smk Islam Al Hikmah Mayong Jepara, SKRIPSI, Teknik Informatika UMK, https://eprints.umk.ac.id/4241/1/HALAMA N_JUDUL.pdf

Latubessy, A., dan Ashari, A., 2012, IMPLEMENTASI SISTEM INTERKONEKSI BASIS DATA TERDISTRIBUSI MENGGUNAKAN SOCKET API (Studi Kasus : Sistem KGB Dinas Infokom Provinsi Maluku). IJCCS, Vol 6, No 2: UGM. ISSN 1978-1520. 